\title{
The Dental Strategy
}

The increasing ability of Health Authorities

to contract with

others is moving

further and further

away from a total

GDS provision

of care.
Mike Grace

m.grace.bdj@bda-dentistry.org.uk $t$ is difficult to think of a single word to describe the White Paper Modernising NHS Dentistry - Implementing the NHS Plan that was launched on 19th September. Words that came into my mind included 'official', 'innovative', 'comprehensive', 'clear', 'slick' and 'clever.' But the dominant word that struck me as I read through the document describing the dental strategy was 'control'.

This is a document about who controls the provision of NHS dentistry and how that control will be applied. It is also a document that supposedly tells us how the strategic objectives for NHS dentistry will be achieved, and it is clear, consistent and makes considerable sense from the Government's view. But, as usual, those who devised it have failed to involve the dental profession in drawing it up, which is hardly surprising if the real aim is to increase the degree of control the Government holds over the future of dentistry.

Let us consider the report itself. First, there are some apparently attractive incentives for 'significantly' committed NHS dentists (the word significantly is in the report but not defined). There will be a new Dental Care Development Fund of $£ 4$ million for Health Authorities to use to provide NHS dentistry where people find it difficult to obtain an NHS dentist. A further $\mathfrak{E} 18$ million will give

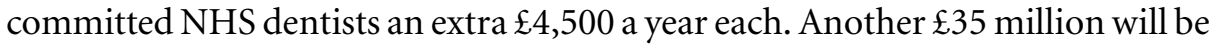
given to Health Authorities to improve and modernise the practices of NHS dentists. Finally $£ 2$ million will help support clinical governance, CPD, clinical audit and peer review. Quite a lot of money, but we must remember that money transfers power and control, and there is still no free lunch.

Second, Health Authorities have a substantial role in the delivery of this finance, and the new strategy intends to increase the responsibility of Health Authorities over which it will have much more control. They will be expected to 'assess local needs and make contracts' (again the wording in the document) to ensure that Tony Blair's promise of access to NHS dentistry for all by September 2001 is a reality. These contracts are unspecified, but will doubtless involve the PDS and CDS, as well as local groups of dentists and corporate bodies. Presumably the hope is that this will redress the access problem that has been created because of the low fees paid for items of care under the NHS, and instead of paying dentists a realistic fee scale the Government is simply trying to take over the provision of care under a salaried system that they have much more control over.

Third, the report looks at quality and comments on how the Government will publish new guidance on complex treatments (in other words prior approval), reform orthodontic treatment and reconsider the interval between dental checkups. While all of these are sensible moves for the person paying the bill, are they not also another subtle shift in who controls what we provide for patients?

Perhaps some would applaud these movements in control, others would say they are to be expected, while still others would fight to retain their freedom. After all, if the Government is paying the bill it has the right to decide how to make its money work most effectively for its own basic objective - to be reelected. There is no doubt that most of the plan should benefit patients, as long as the promises made on finance and action are kept. There is also no doubt that some of the suggestions in the plan are exciting for dentistry in the future.

But we also have to consider some of the slightly ominous phrases in the introduction of the report, referring to the fact that the traditional ways of providing NHS dentistry are no longer appropriate and that the Government will make the best use of resources to help people get more from NHS dentistry. Our freedom of the past 50 years is under threat. For many that may not matter. For some that may be welcome. Only time will tell. 